Chapman University

Chapman University Digital Commons

Summer 8-2020

\title{
Lessons from Hybridity: A Look into the Coupling of Image and Text in Karen Tei Yamashita's Letters to Memory, Claudia Rankine's Citizen: An American Lyric, and Ilya Kaminsky's Deaf Republic
}

Elizabeth Chen

Chapman University, elchen@chapman.edu

Follow this and additional works at: https://digitalcommons.chapman.edu/english_theses

Part of the Literature in English, North America, Ethnic and Cultural Minority Commons

\section{Recommended Citation}

Chen, Elizabeth. Lessons from Hybridity: A Look into the Coupling of Image and Text in Karen Tei Yamashita's Letters to Memory, Claudia Rankine's Citizen: An American Lyric, and llya Kaminsky's Deaf Republic help. 2020. Chapman University, MA Thesis. Chapman University Digital Commons, https://doi.org/ 10.36837/chapman.000196

This Thesis is brought to you for free and open access by the Dissertations and Theses at Chapman University Digital Commons. It has been accepted for inclusion in English (MA) Theses by an authorized administrator of Chapman University Digital Commons. For more information, please contact laughtin@chapman.edu. 
Lessons from Hybridity: A Look into the Coupling of Image and Text in Karen Tei Yamashita's Letters to Memory, Claudia Rankine's Citizen: An American Lyric, and Ilya Kaminsky’s Deaf Republic

\author{
A Thesis by \\ Elizabeth Chen \\ Chapman University \\ Orange, CA \\ Wilkinson College of Arts, Humanities, and Social Sciences \\ Submitted in partial fulfillment of the requirements for the degree of \\ Master of Arts in English
}

August 2020

Committee in charge

Rei Magosaki, Ph.D., Chair

Joanna Levin, Ph.D.

Justine Van Meter, Ph.D. 
The thesis of Elizabeth Chen is approved.

\section{Rei Magasaki}

Rei Magosaki, Ph.D., Chair

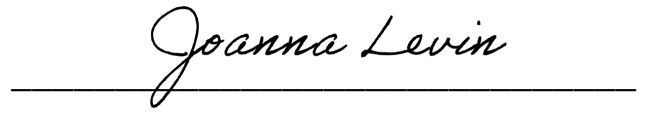

Joanna Levin, Ph.D.

zk Var Meter

Justine Van Meter, Ph.D.

August 2020 
Lessons from Hybridity: A Look into the Coupling of Image and Text in Karen Tei Yamashita's Letters to Memory, Claudia Rankine's Citizen: An American Lyric, and Ilya Kaminsky's Deaf Republic

Copyright $\odot 2020$

by Elizabeth Chen 


\begin{abstract}
Lessons from Hybridity: A Look into the Coupling of Image and Text in Karen Tei Yamashita's Letters to Memory, Claudia Rankine's Citizen: An American Lyric, and Ilya Kaminsky’s Deaf Republic

by Elizabeth Chen
\end{abstract}

The spoken and written word has always been a platform for voices to be heard, but being heard is not always enough. This thesis focuses on the use of hybrid forms in recent publications that address this issue, placing images alongside the written word, letting readers also personally visualize and interpret a perspective different from their own. Specifically, it will look into three examples of hybrid literary works: the placement of photographs beside epistolary writing in Karen Tei Yamashita's Letters to Memory (2017), the blend of visual art and lyric prose poetry found in Citizen: An American Lyric (2014) by Claudia Rankine, and the instructional sign language placed beside the poems in Deaf Republic (2019) by Ilya Kaminsky. I argue that these contemporary writers use the hybrid format to move beyond being "heard," in their attempt to "teach" its audience about underrepresented realities in a way which reminds us of how illustrations help children understand and imagine stories before their transition to imageless texts. In looking at these three works, new possibilities for understanding the marginalized come to being, shedding light onto the importance and immediacy of the subject matter. While these three works each emerge from distinctively different backgrounds, I place them in conversation with one another to demonstrate different ways in which their words unfold the spectacle beside the existence of the spectator. 


\section{TABLE OF CONTENTS}

Lessons from Hybridity: A Look into the Coupling of Image and Text in Karen Tei Yamashita's Letters to Memory, Claudia Rankine's Citizen: An American Lyric, and Ilya Kaminsky's Deaf

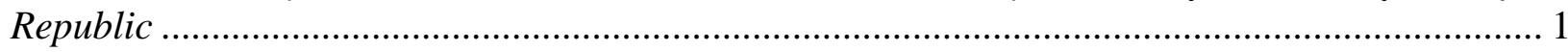

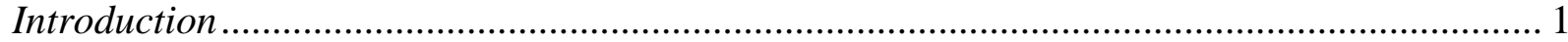

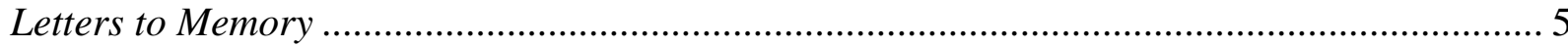

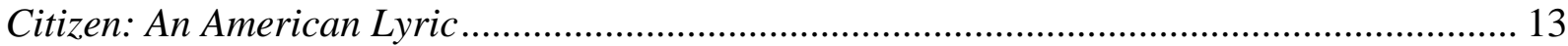

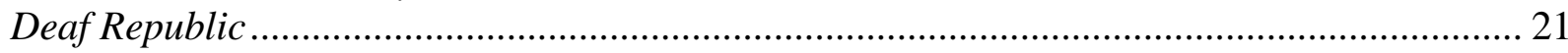

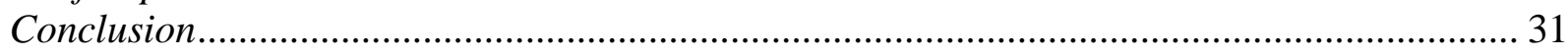

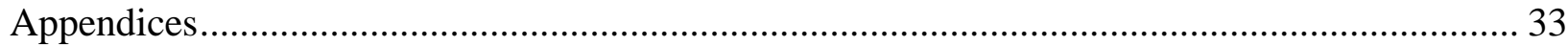

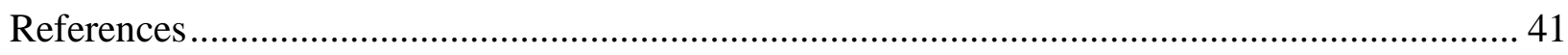

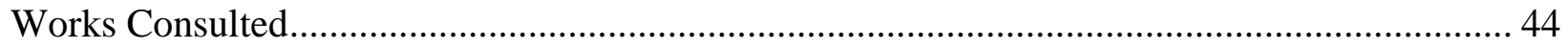




\section{Lessons from Hybridity: A Look into the Coupling of Image and Text in Karen Tei Yamashita's Letters to Memory, Claudia Rankine's Citizen: An American Lyric, and Ilya Kaminsky's Deaf Republic}

\section{Introduction}

The focus of this analysis is on three seemingly unrelated contemporary works from three authors of substantially different cultural backgrounds in the United States. Karen Tei Yamashita's Letters to Memory (2017) is an epistolary memoir. Letters to fictional addressees are pieced together with collections of photocopied items from the Yamashita Family archives at UC Santa Cruz in an attempt to preserve her family's story of Japanese internment during World War II. Claudia Rankine's Citizen: An American Lyric (2014) is a collection of visual art and prose poetry that reflects on the racism that shapes Black lives in the United States. Following these two works, Ilya Kaminsky's Deaf Republic (2019) is a collection of narrative poetry supplemented with a series of illustrated sign language. It tells the fictional story of a town, Vasenka, that goes deaf when a gunshot kills a boy in the middle of town. ${ }^{1}$

Each work is a part of three different conversations not usually brought together, yet they share a reliance on hybrid forms of literature to provide insight for a nuanced culture attached to a minority identity within the United States. The three works also approach perspectives on underrepresented realities, and all three works interweave visuals with text in a way that make it nearly impossible to ignore either the placement of the spectator or the identity of the spectacle.

There are a number of ways to consider why these writers decided to publish their works in hybrid forms. For one, every medium has its limitations when taken by itself. The coupling of

\footnotetext{
${ }^{1}$ According to "Gunshot" from Deaf Republic, the situation happens in Vasenka's Central Square (Kaminsky, 11).
} 
text and visual mediums opens up possibilities for overcoming such restrictions. The spoken and written word has always been a platform for previously ignored voices to come into being, yet to be heard does not always mean to be understood. Ferdinand de Saussure's theories on the disconnect among the sign, the signifier, and the signified in his Course on General Linguistics (1916) illustrate this point, where the “... linguistic sign unites, not a thing and a name, but a concept and a sound-image," with the "concept" being coined as the "signified," the "soundimage" coined as the "signifier," and the relationship between them, arbitrary (Saussure 826). Hélène Cixous in "The Laugh of the Medusa" (1976) points to another limit of the written language more generally, with narrative representation bound by masculine social roles in a Western culture (879). A similar kind of limitation can be said about the image. A photograph, for example, is limited in its depiction of reality. Susan Sontag makes clear that, "[t]he photographic image [...] cannot be simply a transparency of something that happened. It is always the image that someone chose; to photograph is to frame, and to frame is to exclude."2 Onlookers of photographs should be vigilant and understand that they are looking at fragmented parts of a perception of reality that is displaced from the truth. When one comes across a photograph of a tree it is not a proper representation of nature, when one looks at a picture of a man it is not a picture of mankind, and if one were to see a photograph of water, it is not the sea. ${ }^{3}$ And, in the broader scope of the visual art, Gunther R. Kress and Theo van Leeuwen argue in Reading Images: The Grammar of Visual Design (2010) that, “[v]isual language is not—despite assumptions to the contrary-transparent and universally understood; it is culturally specific" (4). In this sense, such culturally-specific visuals can lend insight into a culture when the English language is disconnected from the culture it is attempting to communicate, and the ability text

\footnotetext{
2 Sontag, Susan. “Looking at War: Photography's view of devastation and death.” The New Yorker. 2002.

${ }^{3}$ From Neil Postman's Amusing Ourselves to Death (1985), p. 72.
} 
has to extrapolate nuanced and abstract ideas can also provide understanding to culturallyspecific visuals that could otherwise be lost to onlookers who do not identify with the visual's culture of origin.

It is possible to consider a bleaker theory, that mixed media publications in contemporary literature not only retain these limitations, but are even more limited, made as a response to our present entertainment culture - that, in effort to keep the attention of the reader in our current generation, literary publications have resorted to incorporating visuals to keep the pages entertaining and the word count per page at a minimum. Such ideas are prevalent in the digital age of publication, in which much advice on formatting online articles, blog posts, and e-mails warns against clustering too many words together without any visuals and encourage writers to make sure there is ample white space to give the reader's eyes a break as they scroll down the screen. I consider such a perspective as "bleak" because it suggests that contemporary literature in the United States has also fallen to the pressures of entertainment culture in the digital age, and thereby also creates products for entertainment for mass consumption. I would like to make clear, however, that I am not suggesting that literature should not be entertaining; on the contrary, literature can serve many purposes simultaneously and, in a general sense, functioning under the broad category of entertainment is not what should be of concern. ${ }^{4}$ What should be of concern is when the subject of the literary work provided as entertainment is not inherently suitable for entertainment. Similar to the devastating reality of how readily available war can be shown as a spectacle on television, if the selected works on remembering Japanese American internment (Yamashita), on making visible a systemic racism that kills Black people (Rankine), and on surviving through martial law (Kaminsky) were made to be a spectacle, it would only further

\footnotetext{
${ }^{4}$ At least, it should not be analyzed in-depth for this essay.
} 
prove that war, oppression, and tragedy are merely another kind of spectator sport for those privileged enough to not be chosen by others to perform as part of the spectacle.

I believe in a more optimistic possibility, in suggesting that audiences are not homogeneously affected by the entertainment industry, and that some hybrid texts are the next step in bridging disconnected cultures, understanding mixed cultures, and promoting the intermingling of opposing cultures in a globalized world. Homi Bhabha posited the idea of a "third space" for hybridity, where there is the freedom to reformulate the binary views, where "[t]he process of cultural hybridity gives rise to something different, something new and unrecognizable, a new area of negotiation of meaning and representation" (Rutherford 211). Bhabha was speaking of cultural hybridity at the time, but it is worth noting that these three works from authors of different backgrounds each create "third spaces" for those of similar identities and histories, presented in publications that are hybrid in form. Placed side by side, the three works provide spaces where the cultures hold similar collective memories (oppression, war, unjust institutions, being a spectacle in the face of tragedy) and spaces in which the differences do not intermingle and mold an identity (precarity of Black lives in the United States, Asian American identity politics emerging from a history of immigrant exclusion and internment, or deafness, and being a civilian in a war-torn territory).

Kress and van Leeuwen point out, among many patterns, the inverse relationship between image count and reading comprehension as a reader grows from illustrated publications to college-level texts and note that the appearance of the visual beside text signifies that an audience of less-capable readers is being addressed by the writer (24). Parallel to this, I contend that hybrid texts such as Letters to Memory, Citizen, and Deaf Republic provide a kind of scaffolding for those who do not identify with and wish to better understand the culture 
addressed in these works. Placing a visual beside text in literary works offer important insight that may otherwise be overlooked in an imageless text for the reader whose references are shaped outside of the given culture. In the case of contemporary multicultural publications such as these, the use of the hybrid format "teaches" its audience the same way illustrations help children understand and imagine stories in their transition to imageless texts.

However, while I compare the use of these hybrid formats to the transitional steps children have in the process of learning the world around them, I am not arguing that the end goal in these hybrid texts creating hybrid "third spaces" is the imageless text. In their analysis of this correlation, Kress and van Leeuwen argue that "[...] the opposition to the emergence of the visual as a full means of representation is not based on an opposition to the visual as such, but on an opposition in situations where it forms an alternative to writing and can therefore be seen as a potential threat to the present dominance of verbal literacy among elite groups" (17). Keeping in mind the elitism of language and education in the English-speaking parts of the world, it is possible that hybrid media texts cultivate a critical perspective. The use of hybridity may offer access for a larger audience by diminishing the emphasis on such presumed dominance of verbal literacy, possibly making the imageless publication a less desired end-goal.

\section{Letters to Memory}

Karen Tei Yamashita's Letters to Memory reads as a hybrid epistolary memoir that pieces together fragmented parts of her family's story in Japanese internment and their journey through the years of World War II. Throughout these pages, photocopies of family archives provide personal and intimate snapshots of history. What started as the necessary clean-up after the passing of her late aunt, Kay, became an insightful journey — for both Yamashita and her 
reader-into the historical events that shaped her family's life. Shuffling through letter correspondences, official memoranda, postcards, and other artifacts, Yamashita follows the years of each family member in the generation before hers, mapping out their travels to court, to internment, to war post, to college campuses, each of them with their own kind of pessimistic or optimistic fire carried through the years.

Yamashita recalls that "[t]his project began for me, with the initial retrieval of a folder of carbon-copied wartime letters from Kay Yamashita to her family. And there were also the photographs and collected artwork of Tomi Yamashita that I've kept over the years since her passing in 1972" (171). It can be assumed, here, that the "letters" Yamashita writes to poverty, modernity, love, death, and laughter collected in Letters to Memory are written in reflection and in response to the accompanying visuals of photocopied archives in an effort to make sense of what is snapped from the past for memory. Susan Sontag notes on the mnemonic role of photography as a newly introduced medium of expression that "the photographic exploration and duplication of the world fragments continuities and feeds the pieces into an interminable dossier, thereby providing possibilities of control that could not even be dreamed of under the earlier system of recording information: writing" (156). Such insight can lend reasons for why Yamashita has difficulty grappling with the snapshot pieces of her family history. Given photographs that fragment the continuities of their history, she uses writing as her means to try and gain understanding of information controlled by another.

I argue here that while not all visuals in Letters to Memory are photographs, the photocopied archival materials provided in the memoir have the same rhetorical function as photographs do, and therefore when writing about photographs in relation to Letters to Memory, I include them alongside my discussion. For one, in being photocopied, a piece of reality is 
reproduced as an image by taking advantage of how light reflects against objects in the duplicating process, similar to a camera's use of light to duplicate reality. A photocopied newspaper clipping for example (Appendix A), becomes a visual in which its paper quality, its aging color, its font choice, its edge cut around the article, and the shadows that appear where the paper had been folded, are all vital information captured by a light source and become its own kind of snapshot, plays its own part in the storytelling of a moment in history, and can be utilized in the control of information that Sontag mentions. ${ }^{5}$ In addition, Sontag notes that through “image-making and image-duplicating machines, we can acquire something as information (rather than experience)" (156). This adequately summarizes Yamashita's situation, in which she laments, perhaps unfairly, that as a child she did not understand the importance of a family's history and now must gather the information through photographs, rather than through an immersive experience:

$[\ldots]$ we children thought that they were nostalgic packrats. Now we are old and nostalgic ourselves and comb through this business like we invented it. We pass PDFs and HTMLs over e-mail, google this and that — amateur historians, trying to compensate for the fact that as kids we were too distracted by the idea of this past to be actually immersed in it. Shame on us. Now they are all dead, and we didn't save their brains either. (35) Here, the procuring and reviewing of her family archives becomes, for her, the attainment of her family's information, with her family's experiences as a separate entity needing to be fleshed out somehow and made whole. By the end of these letters, one thing made clear is how little of the past is captured with each snapshot of history. As Sontag asks, "[a] photograph is supposed not to evoke but to show. That is why photographs, unlike handmade images, can count as evidence.

\footnotetext{
${ }^{5}$ As quoted previously, how a photograph "cannot be simply a transparency of something that happened. It is always the image that someone chose; to photograph is to frame, and to frame is to exclude."
} 
But evidence of what?"6 In Yamashita's letter to Ishi in "Letters to Modernity," she writes that Homer, her previous addressee in her "Letters to Poverty," thought "[ ...] with the historian's view that [her family] knew what was happening to them was significant and wrong, that justice might not happen in their lifetimes. What they saved shows that this is true [...]" (35). She reasons here that the storing of all their past photographs and letters passed around through the years of war functions as evidence of not any particular information specific to the moment such a photograph was taken or letter created, but of a greater reality in living through injustice; yet, she backtracks later on within this same letter to concede that she may ultimately be unsuccessful in her endeavors to understand her family's reasons, saying, "[f]orgive me; it is taboo to speak of the dead. But they are my dead, and I fear the reasons for which they saved these letters and how here I must necessarily fail" (Yamashita 35).

This uncertainty of the past is a tone that is consistent throughout the memoir's narrative. The collection of letters and archives starts with an invitation to the reader to "examine and peruse" her family archives and continues with humility to say, "I admit mine is a different or particular way of reading and seeing our story, and I ask only for your curiosity and careful intelligence. Reader - gentle, critical, or however, I count on you, as another guide through this labyrinth" (Yamashita $\mathrm{x}$ ). What is interesting about this invitation is that the reader is asked to be a guide through her family's own history while simultaneously creating distance between the reader and the story.

Set up as an epistolary piece, Letters to Memory places the reader as the outsider to the situation between writer and recipient. Because letters are inherently conversations between two people, the dialogue throughout the narrative places a personal and intimate connection between Yamashita and each of her addressees in which we, the reader, become the other who is peeping

\footnotetext{
${ }^{6}$ Sontag, Susan. "Looking at War: Photography's view of devastation and death.” The New Yorker. 2002.
} 
into a conversation on another's personal life as she tries to fill the holes left by family portraits, hand-written letters, legal documents, and newspaper clippings, all providing limited glimpses into spatial and temporal pasts.

As such, the deliverance of these letters unfolds layers of displacement. It is impossible to separate the memoir's existence from the concept of othering and the existence of the outcast. Like how family members are labeled as outcasts in these letters (Yamashita 44), the reader is also placed as an outsider to the situation, even when provided the closest representations of a history where relocation and internment was a family's reality. In addition, because of the power dynamics that come inherently with epistolary writing - one of the writer with information to be provided to the addressee-it is usually the writer of the letter that commands the conversation and indirectly provides information to the reader, who is not the addressee, who then gathers information about both parties through context. As such, it is the conversation that guides the reader of letters through understanding the situation, not the other way around. This works in contrast with Yamashita's call for a guide most researchers of an archive do not have when sifting through massive collections of preserved information. In suggesting that such readers be a guide for Yamashita through her own family history, the reader acts simultaneously as a learner of another's culture and history, in the sense that the reader is the recipient of new informationa majority of it also new to Yamashita as she sorts through them with her letters — and as a guide, one who must be placed either beside or before Yamashita in the learning process, if they are to guide her.

This placement of the reader contrasts the power dynamics mentioned above and in turn, highlights the displacement Yamashita has with her own history. Like the reader, she is actually also an outsider to and a spectator for her family's past. Here, I use "spectator" in relation to the 
way Sontag explains how photography makes the content being photographed as part of a "system of information" for storage and classification, one in which, "reality as such is redefined - as an item for exhibition, as a record for scrutiny, as a target for surveillance" (156). Indeed, this idea of being a target for surveillance plays a part in Yamashita's feelings when she writes, "And how creepy is it to request from the National Archives the War Relocation Authority files of the Yamashita siblings and then to receive several hundred pages of incarceration documents systematically saved?" (39). In duplicating parts of these archives as visuals for the reader, these visuals placed beside her text then help to communicate a unique experience that is a derivative of Yamashita's own: one of being a spectator to her own family treated as a spectacle, and one of having to shuffle through information gathered from nothing more than photographs snapped by another and documents always addressed to someone else.

Visuals and letters then, through this perspective, do more than address the human spectator and the human spectacle. Here, in Letters to Memory, they also solidify and "teach" the average reader on the existence of the outcast in the American narrative, specifically one that is Asian American. The function of the visual is indeed to see into the past, but of a kind of past in which a family history is evidently altered and recorded by another. Yamashita delves into her own process in balancing her American identity with her Japanese American culture throughout her letters. She writes on a "cultural jeopardy," one in which she feels she is "about to lose something," with that "something" being her Japanese heritage (Yamashita 46). This sense of loss is among the reasons why cultural specificities of individual Asian American experiences should be valued. In Lisa Lowe's landmark essay, "Heterogeneity, Hybridity, Multiplicity: Marking Asian American Differences," she identifies "disruption and distortion of traditional cultural practices $[\ldots]$ not only as a consequence of immigration to the United States, but as a 
part of entering a society with different class stratifications and different constructions of gender roles" (Lowe 25). However, when we see Yamashita chase after an understanding of her culture and its history, other issues arise. After she borrows from a library Ruth Benedict's The Chrysanthemum and the Sword, an early bestseller contributing to Western understandings of Japanese traditions, Yamashita comes across a conflicted conversation with her mother, Asako, with Asako being offended and stating, "We are not Japanese," further complicating definitions of her cultural identity (47-49). In these pages, we see Yamashita as an Asian American looking to outside sources in effort to gain information about her own family's heritage, trying to balance her identity somewhere between Benedict's definitions and Asako's, and we see Asako refuting the validity of such resources written and solidified by the Western writer. For Asako, it is perhaps from having lived through the exclusion and internment throughout the war, in having been mislabeled as the enemy, that she responds in such a way when the line between being Japanese and being Japanese American is blurred. In this instance, readers can get a sense of the difficulty in achieving a totalizing view on a personal identity, a struggle that many Asian Americans face in the United States narrative. In this struggle, Letters to Memory becomes a part of that "third space" that sits somewhere between what is strictly "Japanese" and strictly “American.”

Yamashita also shows that cultural disparities within a single generation happens within her own family, which Lowe had theorized by contrasting the "vertical generational model" with the "horizontal relationship" in Asian culture (26). Specifically, Lowe analyzes a short story in which "two young women avoid the discussion of their Chinese backgrounds because each desperately fears that the other is 'more Chinese,' more 'authentically' tied to the original culture..." than the other and observes that "[t]he story suggests that the making of Chinese- 
American culture - how ethnicity is imagined, practiced, continued — is worked out as much between ourselves and our communities as it is transmitted from one generation to another" (27). In Yamashita's case:

The first two children, Susumi and Kimi, were sent to be educated in Japan; they were entirely bilingual kibei, returning to the United States in the decade before the war [...] The next two children were Chizu and John. Then Iyo, Kay, and Tom. Of course this is my interpretation, but Neech and Neich, having lived away from the family in Japan, seemed to be titular or honorary first son and first daughter. The practical job of elder sibling authority was assumed by Chizu and John, the first fully American daughter and son. (46)

Within the text, we see Yamashita negotiating the identity founded on Japanese traditions of hierarchal structures reliant upon order of birth, with the identity founded on what it means to her to be "fully American."

But through these letters, non-Asian American readers learn something else about the Asian American culture - that rarely, is an Asian American ever labeled to be what Yamashita calls "fully American." As Yamashita details in these letters, a majority of the time, Japanese Americans are labeled as such, with the 'Japanese' placed before the 'American' title. In other moments, they are labeled as "outcasts," with exclamatory marks for emphasis (Appendix B), such as in the photocopied pamphlet cover (Yamashita 44). In times of war, they are sometimes "informants," and in the archives, they can also be labeled as "spoilage," "salvage," or "residue" (Yamashita 38-39). And, "if the designation informant bites, think about the garbage narrative here invoked. Waste, debris, trash, wreckage, refuse" (Yamashita 40). In the case of Letters to 
Memory, its hybrid presentation for the reader provides, for the average reader, a deep dive into both a history and a culture threatened to be forgotten.

\section{Citizen: An American Lyric}

In a conversation separate from Yamashita's letters and archives, Citizen: An American Lyric by Jamaican-born US writer Claudia Rankine is a collection of prose poems and essays interspersed throughout seventeen works of selected art by contemporary visual artists Kate Clark, Toyin Odutola, Glenn Lignon, and Mel Chin, among others. Its second-person prose poetry places readers in a position of experiencing Black lives in the United States with its accompanying art portraying a similar reality through photographic representations and artistic renderings.

Also unlike the images from Letters to Memory, the visuals in Citizen are not archival by any means. Much of the art in Citizen makes the spectator very much aware that they are doing only that: spectating, but in a way different to how Yamashita allows us to spectate with her, her family's history. For Citizen, the focus is on the appreciation of art, in itself, as an act of observing a spectacle of artistic form, usually done in silence. Rankine explains in an interview, "I was attracted to images engaged in conversation with an incoherence $[\ldots]$ in the world. They were placed in the text where I thought silence was needed, but I wasn't interested in making the silence feel empty or effortless the way a blank page would." ${ }^{7}$ From the first image invoking legalized racism, Jim Crow Rd. (2008) by Michael David Murphy, to the last image representing historic racism, The Slave Ship (1840) by Joseph Mallord William Turner, nothing can be done

\footnotetext{
${ }^{7}$ Rankine, Claudia. Interview by Lauren Berlant. BOMB Magazine. 1 October 2014.
} 
to these images but to view them in silence and then eventually turn the page and move on. ${ }^{8}$ When considering this with the reality of failing to see Black people as people, Citizen asks us what we're really seeing, as spectators, in these moments of textual silence and visual representation.

Take, for example, the photoshopped image, Public Lynching (Appendix C), nested between two pieces dedicated to the memory of Trayvon Martin and James Craig Anderson (8895). The image comes from Ken Gonzales-Day's Erased Lynching Series, in which the victims of the lynching are removed from the scene. In "Unnatural Landscapes," Ikyo Day points out how Gonzales-Day's project moves the focus to the spectators, producing visibility out of erasure, and, more profoundly, makes the viewers " $[\ldots]$ consumers of the spectacle of racial violence and participants in their circulation" (Day 75). Because the view is from the ground, below the tree, it is assumed that the view is from the crowd. There is an agreed-upon layer of social privilege that comes packaged with the perspective in these images, and such privilege is, at times, also forced onto the viewer. In being situated in places outside or away from circumstance, such as in Public Lynching, we are reminded that the subject is a silent spectacle, with readers performing the role of the spectator, viewing reality as an outsider through media that only transcribes reality. ${ }^{9}$

When asked about why she titled her book Citizen in an interview with NPR, Rankine makes clear an already-apparent racial schism in the United States:

\footnotetext{
${ }^{8}$ See also, Bella Adams' analysis on Rankine's use of the Hurricane Katrina scripts and Turner's Slave Ship painting representing the 1781 Zong massacre in "Black Lives/White Backgrounds: Claudia Rankine's Citizen: An American Lyric and Critical Race Theory." Comparative American Studies: An International Journal, December 2017, pp 5471.

${ }^{9}$ For additional thoughts on hybridity in Citizen, we can also refer to the hybridity of using text as visual: the fading text with the lines repeating "In memory of..." (134-135), and the stencil piece repeating "I do not always feel colored" and "I feel most colored when I am thrown against a sharp white background" (52-53). However, because this analysis focuses on the coupling — not the blending — of text and visual, it is not included in-depth for this paper.
} 
There are two worlds out there; two America's out there. If you're a white person, there's one way of being a citizen in our country; and if you're a brown or a black body, there's another way of being a citizen and that way is very close to death. It's very close to the loss of your life. It's very close to the loss of your liberties at any random moment. ${ }^{10}$ These two worlds, two bodies, are what the reader experiences with the narrator's guidance throughout the pages of Citizen. In contrast to Letters to Memory, the identity of Black culture in the United States is not dependent on being "fully" or partially "American," but on which of the two bodies of America the spectator places you — one of privilege, or one of being close to death. With a majority of pieces written in second-person, the dynamic is already one of separation with its own inherent power dynamic, for the usage of the "you" implies the existence of the "I," with a separation that is controlled by the "I." It is usually the narrative "I" that tells the "you" what it is that keeps the two as separate bodies—-both fully American, but of different American worlds.

Also unlike the epistolary format of Letters to Memory, the use of second-person in Citizen is not for establishing a close relationship between the "you" and the writer. In Citizen, the narrator is not always the same person as the author, as every piece of Citizen stands as its own experience independent of others, where the relationship between the "you" to the "I," is not always immediately clear to the reader. In The Hatred of Poetry (2016), Ben Lerner writes on a moment when, while reading Rankine's piece on the appointment the "you" has with a trauma therapist, he initially identifies with the "you" but realizes at the end of the piece that, due to his own race and privilege, he actually identifies more with the "I," thereby making the two pronouns in-exchangeable (70-71). Here, is an excerpt from the piece from Citizen:

The new therapist specializes in trauma counseling. You have only ever spoken on the phone. [...]

\footnotetext{
${ }^{10}$ Rankine, Claudia. "In 'Citizen,' Poet Strips Bare the Realities of Everyday Racism.” NPR, 3 January 2015
} 
At the front door the bell is a small round disc that you press firmly. When the door finally opens, the woman standing there yells, at the top of her lungs, Get away from my house! What are you doing in my yard?

It's as if a wounded Doberman pinscher or a German shepherd has gained the power of speech. And though you back up a few steps, you manage to tell her you have an appointment. You have an appointment? she spits back. Then she pauses. Everything pauses. Oh, she says, followed by, oh, yes, that's right. I am sorry.

I am so sorry, so, so sorry. (Rankine 18)

Lerner writes that, “Citizen's concern with how race determines when and how we have access to pronouns is $[\ldots]$ a direct response to the Whitmanic $[\ldots]$ notion of a perfectly exchangeable "I" and "you" that can suspend all difference [...] you are forced to situate yourself relative to the pronouns as opposed to assuming you fit within them" (Lerner 71). While Lerner sees the relationship of "you" and "I" as separable and on opposing ends defined by race, Stephanie Burt ${ }^{11}$ adds to the perspective and poses in the poem is you that the two are related and that the racial identity, while it may or may not be interchangeable, are dependent upon each other:

$[\mathrm{O}]$ nly prior knowledge about her can lead us to envision "you" as black, and sometimes that version of "you" would be wrong. It is no accident that these parts of Citizen have no first-person pronoun, only "you" and "he" and "she": they describe what happens when you do not have an "I" apart from others, when you cannot get wholly outside the way in

\footnotetext{
${ }^{11}$ Citation for her work is under the name used during publication. Refer to citation, "Burt, Stephen."
} 
which other people construct "you" $[\ldots]$ Their constructions depend on what they think they see. (350)

Rather than being forced to be someone or somewhere while reading Citizen as Lerner argues, Burt suggests readers are invited to be a part of the conversation in each essay, and in many moments, “[...] Rankine's 'you' lets you, the reader, ask what you would do, or why you did what you have already done" (Burt 352). Though the two ways of reading the use of secondperson pronouns in Citizen addresses different aspects of the effect of second-person narration, both Lerner and Burt make a point to focus on the lack of control for the reader. For Lerner, a reader is being "forced" to make a choice on who to identify with in a fixed situation; for Burt, the conversation holds no choice in identity—-the "you" is constructed by the "I" and the reader is only able to respond silently. This power exerted by the narrator onto the reader, deployed by the placement of the reader as a passive recipient, a subject without the ability to change the situation at hand, is itself a mimicking of power structures inherent in the systemic racism in the United States.

This specific piece from Citizen is accompanied by a picture of Kate Clark's Little Girl, a sculpture of a crouching deer-like animal with the face of a colored human (Appendix D), described by Rankine as a "black girl's face on an [infant caribou]." "Images like Little Girl act as a visual representation to help the reader grapple with the abstractions of emotions in moments when different identities placed upon a singular individual clash on them. In the text, the "you" is a trauma patient who becomes a victim of racist aggressions. While it is important to note that, here, readers are also only able to view the spectacle as it cowers with a frown before them, the image lays silent while it speaks to something that is personal and distant from the viewer. When interviewed about her collaboration with Clark, Rankine explained that, "Clark

\footnotetext{
${ }^{12}$ Rankine, Claudia. Interview by Lauren Berlant. BOMB Magazine. 1 October 2014.
} 
uses taxidermy to create her sculptures. In the particular piece I used in Citizen [...] I was transfixed by the memory that my historical body on this continent began as property no different from an animal."13 Indeed, in the historical transaction of slaves as property to be bought and sold, there is an erasure of human subjectivity which is inherent in the behavior of the trauma therapist who sees "you" for the first time and is unable to consider "you" as the possible client. The sculpture Little Girl, then, helps make tangible the parts of persistent racism that keep the separation between the "two Americas" Rankine describes.

While some parts of racism are tangible and obvious for spectating, such as police brutality and racist aggression in professional environments, others are not. When delving into what Citizen means to her, Rankine says, "On the one hand, I am talking about institutionalized racism. But on another and, I think, equally important level, I'm just talking about what happens when we fail each other as people." ${ }^{\prime 14}$ Take, for example, this piece from Citizen:

You are in the dark, in the car, watching the black-tarred street being swallowed by speed; he tells you his dean is making him hire a person of color when there are so many great writers out there $[\ldots]$ When you arrive in your driveway and turn off the car, you remain behind the wheel for another ten minutes [...] Sitting there staring at the closed garage door you are reminded that a friend once told you there exists the medical term- - John Henryism — for people exposed to stresses stemming from racism. They achieve themselves to death trying to dodge buildup of erasure. Sherman James, the researcher who came up with the term, claimed the psychological costs were high. You hope by sitting in silence you are bucking the trend. (Rankine 10-11)

\footnotetext{
${ }^{13} \mathrm{Ibid}$.

${ }^{14}$ Rankine, Claudia. 'In 'Citizen,' Poet Strips Bare the Realities of Everyday Racism.” NPR, 3 January 2015
} 
The focus of the text is inherently on the differences not visible to the eye. The "you" is the receiver, one who is within the situation, while the narrator is a close-by observer who is able to explain the situation as it happens in the present tense, one who narrates with an omniscient knowledge of what runs through the mind of the "you." In this placement, the reader transforms into one who deals with the abstractions of race every day. Here, the "you" is grappling with ways to go against the tide. Why, in this example, are writers of color and great writers considered to be separate categories? The mention of John Henryism allows readers to see how racial ideologies affect the mental health of the "you." Here, Citizen deals with the effects that are felt, even though it is not necessarily seen. It is not something that can be recorded on a phone and shared on the internet or photographed as proof of existence for both the spectacle and the spectator, but of an imbalance and vulnerability found within each individual of the collective race when the other "fails to see each other as people." Such failures are just a small sample size of the multiple ways microaggressions permeate all aspects of life.

When we look at the following piece from Citizen, we see an example that is more in line with Burt's argument that readers may ask what they would have done, and is less applicable to Lerner's way of situating a reader relative to the pronouns:

I knew whatever was in front of me was happening and then the police vehicle came to a screeching halt in front of me like they were setting up a blockade. Everywhere were flashes, a siren sounding and a stretched-out roar. Get on the ground. Get on the ground now. Then I just knew.

And you are not the guy and still you fit the description because there is only one guy who is always the guy fitting the description. (Rankine 105) 
The last line in this excerpt is repeated in a series of situations, ending with a final, "[a]nd still you are not the guy and still you fit the description because there is only one guy who is always the guy fitting the description" (Rankine 105-109). Here, the "I" is also the "you," and the two are interchangeable. The "you" is the "I" who has been chased down by the police for a crime that was committed by someone else. There is no choice for us readers on how to "situate" ourselves. You are the one the police sirens are after. I am the one the police sirens are after. You are the one told to get on the ground. I am the one told to get on the ground. Take your pick, they are the same. Readers then, have no escape from being "the guy who is always the guy" because regardless which pronoun they identify with, the result is the same, and the reader, though forced to be a participant of each accusation, has no voice for themselves in each situation that echoes the police brutalities across the United States resulting in the realities of thousands of Black Americans, including the more recent murder of George Floyd. ${ }^{15}$

This intimacy that the reader has with the situation at hand in these pieces because of the use of second-person resonates with the reason for the subtitle, "An American Lyric," the same one Rankine used for her earlier work, Don't Let Me Be Lonely (2004). In an interview with Los Angeles Times when Citizen was published in 2014, Rankine explains that she references lyrics in her titles to "pull the lyric back to its realities" and that, to her, "It always surprises me [...] when people say that the realm of the lyric is the personal and the personal is not political. I just don't know how we can get to 2014 and say that with a straight face" (Ulin). For Rankine, the

\footnotetext{
${ }^{15}$ I would like to add here, respectfully, that "more recent" does not imply more important or relevant compared to others who have been murdered around the same time frame as Floyd but were not named, nor does this imply that no Black Americans have been murdered after him. This sentence is dated and only guaranteed to be relevant up to August 2020.
} 
personal is political ${ }^{16}$, and Citizen forces readers to take in each political prose poem or art piece and make it personal, similar to how Lerner and Burt have interpreted it.

\section{Deaf Republic}

In contrast to Letters to Memory and Citizen: An American Lyric, the 2019 collection of poems in Ilya Kaminsky's most recent Deaf Republic tell a story of a fictional town, Vasenka, abused under martial law. The first half of the collection focuses on the story of the couple, Alfonso and Sonya. The poems juxtapose Eros with Thanatos ${ }^{17}$ in constant succession: the death of Petya and the violence in the public sphere is placed beside flashbacks of intimate moments between the couple, and the birth of their new daughter, Anushka, is placed beside the death of the couple by the end of the first half. In contrast, the second half of the collection holds a narration centered on the life and death of Momma Galya and her days looking after the orphaned Anushka.

The core of the collection is split into two acts and is introduced to the reader in the format of a play, starting with a "Dramatis Personae" listing all the characters to come in the following pages. This format positions the reader as a spectator for the story to unfold on an imagined stage in a theater piece. The collection of poems, in being formatted as a script, assumes a form of entertainment. The existence of this imaginary stage is also emphasized in both the beginning and ending poems. "Gunshot," the first poem of Act One, starts with "Our country is the stage" (Kaminsky 11), and in the last poem, "And Yet, on Some Nights," the phrase is repeated in the line, "[o]ur country is a stage: when patrols march, we sit on our hands"

\footnotetext{
${ }^{16}$ For more on this, refer to the introduction in The Racial Imaginary (2014), in which Rankine writes alongside Beth Loffreda on how it is a mistake to assume that the personal imagination transcends politics, economics, or even race.

${ }^{17}$ This references Freud's concept of a life instinct and a death drive in Beyond the Pleasure Principle in 1920.
} 
(Kaminsky 71), evocative of the Shakespearean line from As You Like It: "All the world's a stage, / And all the men and women merely players. ${ }^{.18}$ It should also be noted that there are consistent parallels drawn between the townspeople and puppets in a puppet show throughout the collection. ${ }^{19}$ Puppets, specifically, are mentioned in seven different poems, each of them related to the death of someone in Vasenka, of someone made into a spectacle, and of someone played like a puppet, whose fight is forgotten, in the end, when, "[y]ears later, some will say none of this happened; the shops were open, we were / happy and went to see puppet shows in the park." (Kaminsky 71).

However, unlike how Shakespeare's lines focus solely on the concept of people having a role to play day in and day out through the seven stages of their life, Kaminsky's lines also focus on the existence of the spectator-the reason a play exists and the reason a show must go on. Even though the poems assume a format that evokes entertainment and the oppression of a town is delivered as a spectacle, the deliverance takes a hard look at the difference between the silence of the oppressed and the silence from those who are watching. ${ }^{20}$

The collection presented as a two-act play is bookended by two poems, "We Lived Happily during the War" and "In a Time of Peace," that speak of the American reality. Below, the lines from "We Lived Happily during the War" position the reader as being part of the American "we" with the narrator who calls for forgiveness while others have their homes torn by the country's focus on money:

\footnotetext{
${ }^{18}$ Refer to Shakespeare's As You Like It, Act II, Scene VII

${ }^{19}$ Refer to the following poems in Deaf Republic: Gunshot, "When Petya, the deaf boy in the front row, sneezes, the sergeant puppet collapses, shrieking."; The Townspeople Circle the Boy's Body, "Behind them, a puppet lies on cement, mouth filling with snow."; What We Cannot Hear, "and what remains of her is / a puppet / that speaks with its fingers,"; Away, "Urine darkens his trousers. / The puppet of his hand dances."; A Bundle of Laundry, "Above the checkpoint, Alfonso's body still / hangs from a rope like a puppet of wind."; The Trial, "Doors and / puppets dangling from their handles, a puppet for every shot citizen."; and And Yet, on Some Nights, "Years later, some will say none of this happened; the shops were open, we were happy and went to see puppet shows in the park."

${ }^{20}$ On the page following immediately after the last poem in Act Two, Kaminsky writes, "[w]e are sitting in the audience, still. Silence, like the bullet that's missed us, spins_-" (72).
} 
And when they bombed other people's houses, we

protested

but not enough, we opposed them but not

enough.[...]

in the street of money in the city of money in the country of money, our great country of money, we (forgive us)

lived happily during the war" (Kaminsky 3)

Readers may interpret these lines to be addressing the United States' willingness to cause war, and the United States' privilege throughout history of profiting from wars that are always elsewhere. However, lines from "In a Time of Peace" points to a greater absent-minded willingness to watch violence and oppression as something distant and irrelevant to the more immediate, happy life lived in supposed peace:

[...] I watch neighbors open

their phones to watch

a cop demanding a man's driver's license. When the man reaches for his wallet, the cop shoots. Into the car window. Shoots.

It is a peaceful country. 
We pocket our phones and go. (Kaminsky 75)

In addition, the later lines from "In a Time of Peace" refer back to lines of previous poems found in Act One:

Ours is a country in which a boy shot by police lies on the pavement for hours.

We see in his open mouth

the nakedness

of the whole nation.

We watch. Watch

others watch. (Kaminsky 75)

Here, our open mouths mimic Sonya's open mouth (Kaminsky 12), and us watching and watching others watch reflects the sign language captioned " $[\mathrm{t}]$ he town watches" and the audience watching as the town watches (Kaminsky 17). ${ }^{21}$ Immediately after is the line, "The body of a boy lies on the pavement exactly like the body of a boy" (Kaminsky 75), which references “The Map of Bone and Opened Valves," another poem in Act One:

Observe this moment

- how it convulses-

The body of the boy lies on the asphalt like a paperclip.

The body of the boy lies on the asphalt

\footnotetext{
${ }^{21}$ Also consider the line, "[b]ehind them, a puppet lies on cement, mouth filling with snow" (Kaminsky 17) in the same poem. The portrayal of a puppet lying in silence, mouth filling with snow, suggests a parallel to Petya lying in silent death, one that, in certain religions, offers a renewal/purification to life in this world.
} 
like the body of a boy. (Kaminsky 16)

This mirroring of lines among poems on Vasenka and the United States also suggest that Deaf Republic calls for conversations on the silence of US citizens as metaphors for consideration in the kinds of silence found in both the townspeople oppressed by martial law and the audience watching a spectacle.

Dispersed throughout the core of the collection are also poems that communicate the personal as opposed to the public, placing the communal beside the private. These poems function like vignettes throughout the play, upsetting the mood and changing the pace of the story, as if interfering anger in wartime with love in small pockets of peaceful moments. Such peace inserted between times of violence is particularly apparent in Act One, in which readers get slots of Alfonso's private moments with his wife, Sonya, amidst all of the disturbances that happen in town as the townspeople stand by and watch. Chronologically, for example, the poem "The Map of Bone and Open Valves" hones in on a moment of death in the town, which is followed by “The Townspeople Circle the Boy’s Body," in which focus on the stillness of a body lying, dead, in public. Descriptions of death in the public sphere is immediately followed by two poems that focus on procreation and the making of life in the private sphere. "Of Weddings before the War" recollects the night of Alfonso and Sonya's wedding with the lines, "I watched you gleam in the shower / holding your / breasts in your hand-" (Kaminsky 18). In the poem that follows, "Still Newlyweds," readers are given another intimate moment with Alfonso and Sonya in the bathroom. "You step out of the shower and the entire nation calms - // a drop of lemon-egg shampoo, / you smell like bees" (Kaminsky 19). Immediately following these two affectionate flashbacks, "Soldiers Aim at Us" throws readers back to the public sphere. Instead of love, there are strong hints of anger, as the poem ends with: 
On earth

a man cannot flip a finger at the sky

because each man is already

a finger flipped at the sky (Kaminsky 20)

When asked about this choice of placement, Kaminsky explained, "I'm trying to show the private lives, and not just the constant public violence. It's not always doom, doom, doom, there are moments of kindness and tenderness always" (Armistead). This placement then, becomes a portrayal that makes the story intimate to reality. The juxtaposition that comes with the order of the poems in Deaf Republic provides a multi-faceted perspective of human spectacles, adding colors to an often dark, one-dimensional portrayals of violent injustice.

Kaminsky also notes at the end of the collection that " $[\mathrm{t}]$ he deaf don't believe in silence. Silence is the invention of the hearing" (79). This idea was touched upon during his interview with The Guardian as well in which he explains, "Pretty much all my childhood and adolescence was spent watching the Soviet Union fall apart, but I couldn't hear, so I followed the century with my eyes. I didn’t know anything different, but now I understand that I was seeing in a language of images" (Armistead). The illustrated sign language visuals scattered throughout Deaf Republic, then, easily becomes an introduction to deaf language and deaf culture for those who have little to no understanding of it. Kaminsky notes that "[d]eaf culture is such a beautiful thing. It has one of the youngest languages in the world and is still developing" (Armistead).

There are two instances in Deaf Republic in which characters use sign language without any illustration. In “Above Blue Tin Roofs, Deafness,” girls sign “start” (Kaminsky 39) and in “And Yet, on Some Nights," readers come across, "Don't be / afraid, a child signs to a tree, a 
door" (Kaminsky 71). In both instances, only text is supplied to tell the story, and in both instances, it is difficult, if not impossible, to imagine what the character is showing with their hands. We may see a child standing in front of a prototypical door or tree, but because the sign language is a language readers may not know, the lack of a visual then translates to a disconnect between reader and story. It is the most evident here that, because deaf language is a visual language, it is necessary for 'deafness' to be seen on the printed page. Even though the writing clearly tells the reader that the people in Vasenka choose to be deaf, the deafness is not seennor can it be experienced — without the illustrations that perform a language in its silence. In being able to visualize the silence speak through hands that draw out words like "town," "kiss," "earth," "story," "army convoy," and "hide" in a different language, readers are given a glimpse of what it is like communicating within a deaf community as an outsider. As a receiver. And in being placed as a receiver, a spectator, what becomes highlighted is the privilege in not being the one forced into silence, in becoming the silent observer who lives happily during the war; however, this is only a beginner's glimpse, for even though captions are placed beneath each illustration to translate it into text, the captions lend limited help. Such limits are explained succinctly by W. J. T. Mitchell in his essay "Ekphrasis and the Other":

A verbal representation cannot represent — that is, make present—its object in the same way a visual representation can. It may refer to an object, describe it, invoke it, but it can never bring its visual presence before us in the way pictures do. Words can "cite," but never "sight" their objects. (3)

Certainly, the incorporation of illustrated sign language is a necessity for the reader who is the learner of another culture — namely deaf culture — particularly because the illustrations add sight to the reader's insight. 
Take for example, the illustration for "match," first seen coupled with the poem "Arrival" (Kaminsky 26, Appendix E). Without a visual, simply the word 'match' could be anything from saying two nouns fit together to a fight ensuing as a result of two or more competitive egos colliding. It is with the visual of one finger pointing toward the palm of another hand with outspread fingers that the reader can come to the conclusion of the tool used to start a fire. One could argue here that because of the line "In the nursery, quiet hisses like a match / dropped in water" (Kaminsky 26), readers are able to conclude on the type of match without the caption; however, it is difficult to say whether a reader would know that the illustration is supposed to communicate "match" without the caption. I would argue that in this instance, without a caption, the reader could possibly guess that the illustration is of any other relevant imagination, such as a finger pointing to a destination. The title of the poem is "Arrival" and without a caption, for example, the image can be taken as 'arriving at a physical space.'

Even more interesting is the visual of the word "match" for Deaf Republic as it appears in the digital version of The New Yorker (Appendix E). Here, the visual is different from the static illustration by Jennifer Whitten provided in the print edition. Animated images by Miwon Yoon show lively fingers with little sparks and flames rising and disappearing above the fingertips (Kaminsky). While the print version does have small strokes above the fingers to insinuate there is also to be movement, it is ambiguous what that movement would be. It is with the digital version that the movement is exact and nothing is left ambiguous in its language, further pressing the necessity of visuals for reader's accessibility to deaf culture. The movement of the fingers imitating flame coupled with the light flick of the fingertip pointing toward the palm, suggest that the emphasis here is in the moment the match gives birth to fire. The sign for "match" then, even though it displays the item in question, becomes a verb through its connotation. In this deaf 
language in Vasenka, the "match" is defined by its relationship to its flame, its ability to spark flame, and in the moment it gives birth a new flame. Such connotations are not possible through supplying only verbal text to tell the story.

In addition, if we were to take "match" as the last line of the poem "Arrival" rather than simply an illustration accompanying the poem, "match" then becomes the closure that cycles back to the poem's aperture, as both lines are referring to birth, of a baby or a flame. Here, the title of the poem might be considered a line of the poem, in accordance with Kaminsky's style of allowing the title to bleed into what is traditionally considered the first line of the poem. Take, for example, the poem "When Mommy Galya First Protested" in which the first stanza follows the title with, "She sucks at a cigarette butt and yells / to a soldier, / Go home! You haven't kissed your wife since Noah was a sailor!" (Kaminsky 52). While the title can be separated from the first stanza, readers can also take the title to be a prepositional phrase that is attached to the complete sentence that forms the entirety of the first stanza. A similar flow happens in poems such as "Soldiers Aim at Us" and "And While Puppeteers Are Arrested," showing that it is important to consider the title as being lines of poems in Deaf Republic. Also, because the illustrations are in fact a language on its own, illustrations can also be considered as lines of poems. Poems written with illustrations, then, become examples of translanguaging between English language and sign language. It should be noted that when illustrations accompany the textual end of a poem in print form, it also accompanies the textual end of the same poem in digital form, although the digital version includes illustrations displayed without textual poems attached to them. This suggests that while the visuals can stand alone, the poems cannot stand without their visuals, and that they must be attached to the textual lines of the poem to keep the poem whole. 
Before the exit poem of the collection, Deaf Republic ends the two-act collection with a page that speaks through solely illustrations (Appendix F). From previous pages, readers can translate the illustrations to mean "town," "the town/crowd watches," "earth," and "story" (Kaminsky 73). First, it is important to note that to make a full translation from Deaf Republic's sign language to English, it is necessary to add prepositions and articles to make the thought complete, even though it may alter the intended meaning of the statement. Should the sentence start with "A town" or "The town"? Also, because "town" is followed immediately with a complete sentence, either "the town watches" or "the crowd watches" depending on the translation, the "town" in the beginning then becomes a subject of a phrase that is placed before "the town/crowd watches," and readers could then garner a translation related to "In the town, the crowd watches..." or "Throughout a town, the crowd watches...," but what are they watching? Readers are given the words "earth" and "story," but with two nouns, we are again forced to place words between to fill in the gaps of understanding. The crowd could, in effect, be watching "the earth tell a story" or "the earth's story." In addition, when we look at the digital version of "story" (Appendix G), the hands start in a closed position and open up, like book covers splitting open to pages, and the translation can also be something similar to watching "the earth unfold a story" or even "the earth finish the story," as the printed illustration is the opposite, with the hands starting open and then gathering together to a close, suggesting a finished book. The latter also makes sense in considering that this page comes right before the exit poem "In a Time of Peace," when the play has finished and the story as effectively ended.

But even though there is a limit to the translation readers can produce, what is important is that there is now an idea that can be communicated without the captions. By the end of Deaf Republic, readers have gained the vocabulary necessary to understand the final page, a full note 
of only sign language, and - like a classroom textbook - if the reader is struggling to pass the review quiz at the end, they can flip back to look up answers in previous poems.

\section{Conclusion}

Photographs in Letters to Memory let readers visualize the distance Yamashita grapples with for the story of her own family's history through war and internment. The visuals in Citizen: An American Lyric present forms of the emotions particular to Black citizens in the United States, and images in Deaf Republic present another language, another culture, to the reader.

The placement of images beside text in these works also reveal similar relationships between those treated as a spectacle, and those treated as a spectator. In Letters to Memory, the Yamashita family is the spectacle, silent with regards to their experiences through the war, with Karen Tei Yamashita acting as a spectator beside readers, toward her own family. For Citizen: An American Lyric, every essay, every visual, points back to the Black citizen as the silenced spectacle, the one shot by a cop in a video before we, the silent spectators, "pocket our phones and go." And, in Deaf Republic, we come across multiple facets of silence and spectatorship, from the dead, the puppets, the townspeople, to the audience. In these instances, the coupling of image and text lets the average reader visualize another culture the way it is experienced by the writer and lets readers take a good, hard look at themselves and at what the world looks like from the view of the narrator. Such hybridity brings forth another kind of representation for "third space" realities that many of the readers do not know and furthers the understanding from the reader of a world that is not of their own, bridging gaps among nuanced cultural identities across the United States. 
Specifically with these three publications for analysis, I conclude that readers are guided in their ways to look and not turn away, especially to all that is lost in the pockets among memories, the parts that are being forgotten or overlooked, yet mold the present. We see in Letters to Memory, how Yamashita is called to remember the internment that affected the trajectory of her entire family's life and still molds her cultural heritage to this day. In Citizen: An American Lyric, it is exceedingly apparent that racial prejudice is so deeply embedded into the societal systems of the United States. The fact that slavery is not legal and that humans cannot, on legal papers, be passed around like property, does not mean that its citizens can claim racism does not exist. And, Deaf Republic, too, warns that all the violence, the struggle of the townspeople and the deaths of the civilians, however painful to watch, can eventually be forgotten, eventually be denied as ever happening and become a story for entertainment. ${ }^{22}$ If we are to be spectators, then look at what is here, in front of us. If we learn to look and see what is there, that is still only the first step in a long bridge across worlds. As Rankine puts it in her last essay in Citizen: "It wasn't a match, I say. It was a lesson" (159).

\footnotetext{
${ }^{22}$ Refer to the same line from "And Yet, on Some Nights": "Years later, some will say none of this happened; the shops were open, we were happy and went to see puppet shows in the park." (Kaminsky 71)
} 


\section{Appendices}

\section{Appendix A: Newspaper Clipping}

ON REVIEW

April 13, 1944

Lease to Jap-Americans Ended; Dr. McKibben Makes Statement Editor, Evanston REvizw: In-
asmuch as an article appeared in
THE REviEw concerning our at- Amed to a Mrs. Dorothy Kitow, an
tempt to fent our home at 2231 American of Japanese descent, born Asbury avenue to Japanese-Ameri- in America, trained in its culture, can people it seems only fair that andies, the University of Colifornia. we be permitted to make a more It happens that her husband wa the situation correct statement of born in Japan, coming to this counthis action. After talking with one of our up in this country, prevented by neighbors who was certainly not stulied becoming a citizen. He very enthustastic about such rental ford university at weland Stan but who raised no fundamental ob- in farming in Californis engaged Japan, we leased our home to this war broke out. The Kitows owned however, Abjections family. Soon, their own home from which they in and some of our neightre ringing doorbells up and down our He was a member of the Rotary street and adjacent streets. We both of community and they are realized that something should be a refined educted coupley are do We invited our near neighors 9-year-old son. to our home for a friendly conferkinds of meetine have held all In attempting to give these people this was the first time we invited an American and we were doing our neighbors to come in and hold a They, and people like them, are protest meeting against us! It was having a desperately difficult time a spirited but fairly friendly finding housing. We would be gla to have them in our home and Wife Is Native of $\mathbf{U}$. $\mathbf{S}$. would ourselves certainly welcome Comment was made to the effect them as neighbors. Americans. Of course that action was thoroughly in harmen exactly what we proposed to do. We with the avowed aims of our present war; namely, opposition to any doctrine of racial superiority such as the Nazis are promulgating. Such tered makes us wonder we encounfighting for anyway, what we are the real meaning of the what is doms. We were much disturbed over some of the speeches made at our home. As one of our neighbors who was at the meeting wrote to think that actually wept family have already given of our service and may be called a year's give their lives for such mouthings of Christian and democratic prin-

Kitows Surrender Lease The Kitows upon being informed of the situation, immediately offered pected ther lease, as we exlive under would, not desiring to would we want them to do. Nor And so ends the matter. Or doe it? This matter is of much greater proportions than just that of neighthe and real estate values. It raises believe in and what Evanstonians for.

Among those present Monday of the hostility did not speak because comment from those outside the neighborhood were: Dr. E. F. Tittle, Franklin R Luccock, Dr. Harrison Ruopp, Mr. and Mro. Rochold Smith, and Dr. H. G. Smith, who was asked to serve as moderato of the meeting. Dr. Roy Smith of we in Pearl Harby for six months after spoke on behalf of the Kitows. present representing the War Relocation authority. Sincerely yours,
Frank M. McKibben

Evanston Review Newspaper, Newspaper Article. Yamashita Family Archives. 
Appendix B: “Outcasts!” Publication

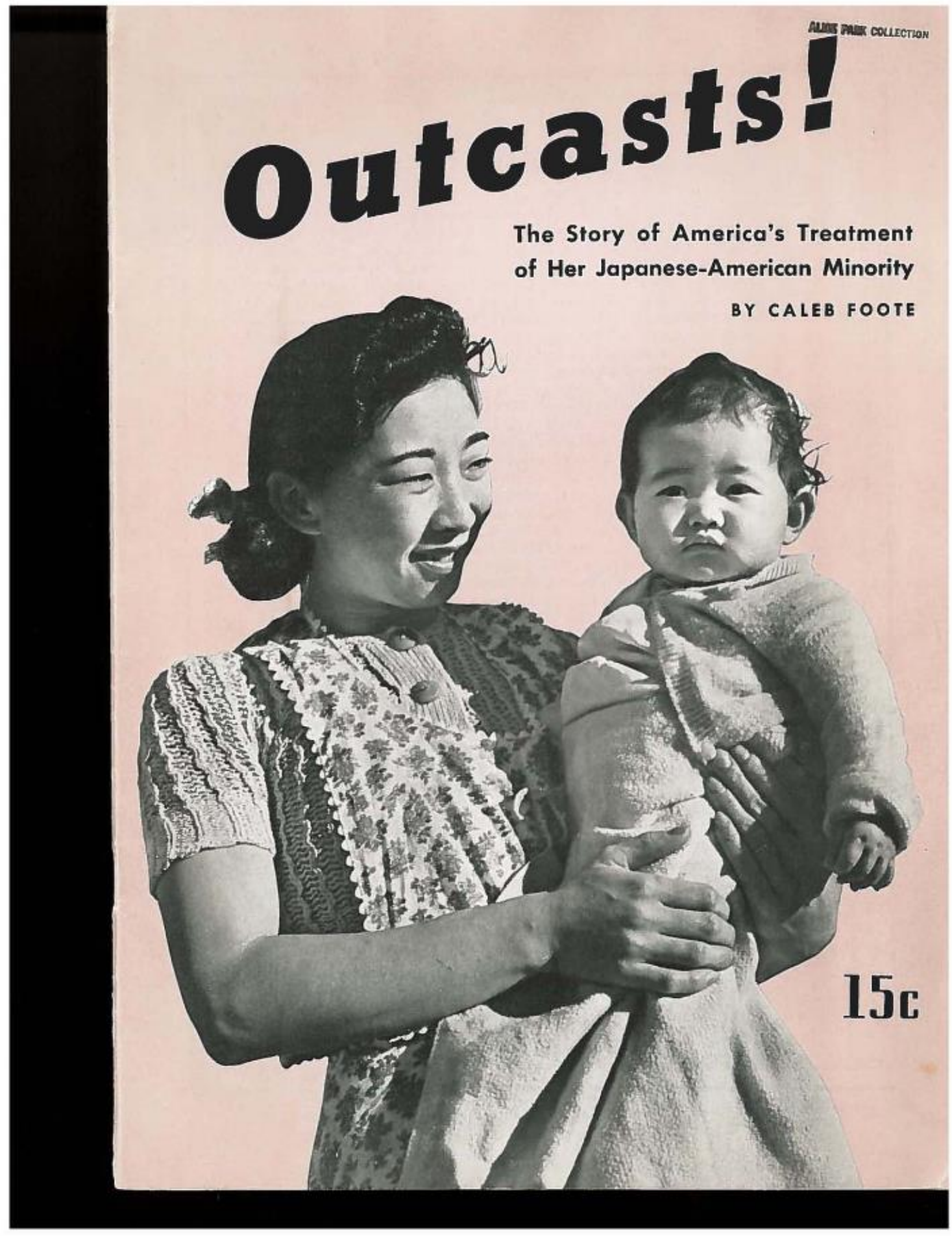

Foote, Caleb. "Outcasts!” Yamashita Family Archives. 
Appendix C: Public Lynching

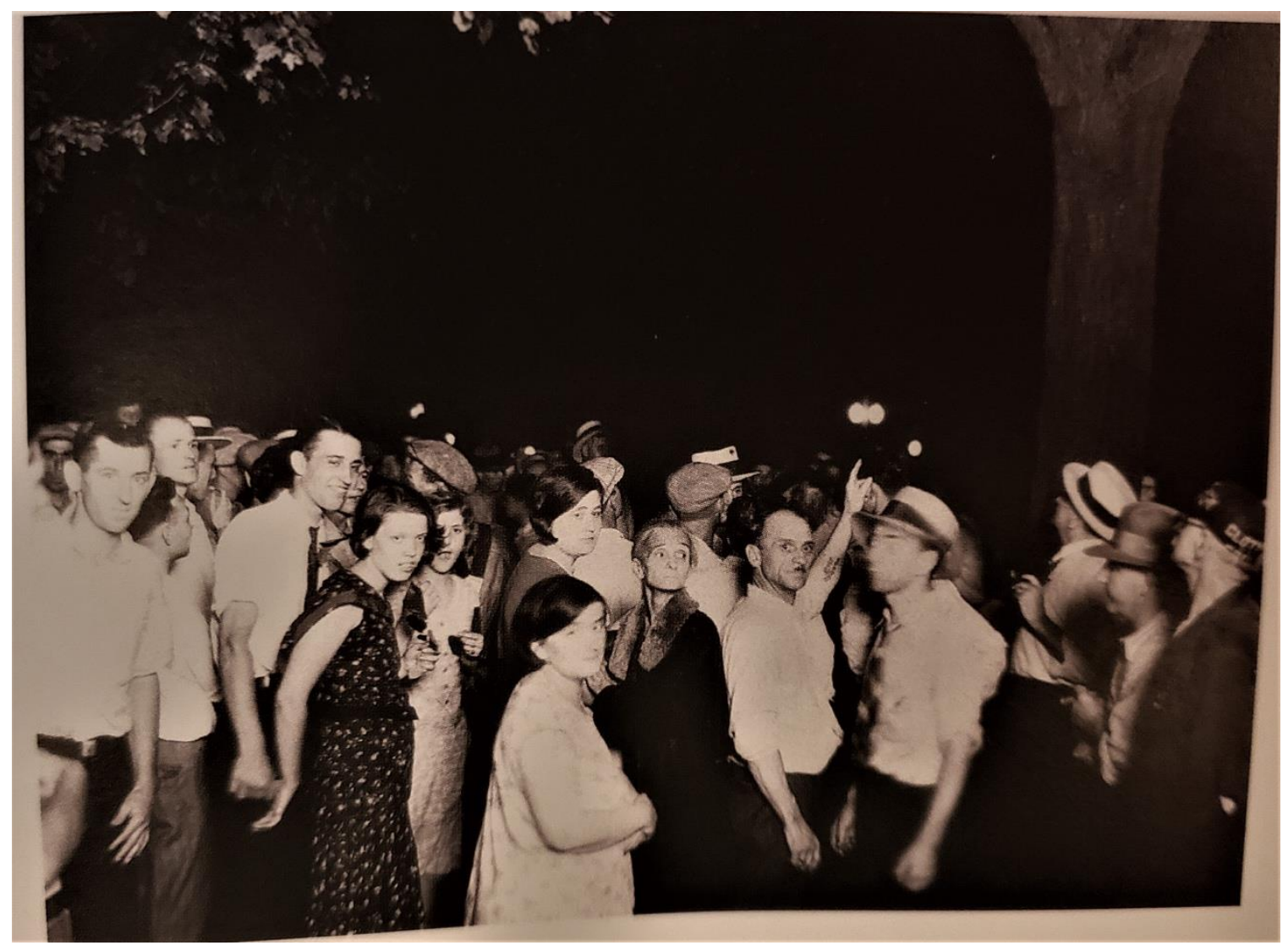

Gonzales-Day, Ken. Public Lynching, from Citizen: An American Lyric, page 91. 
Appendix D: Little Girl

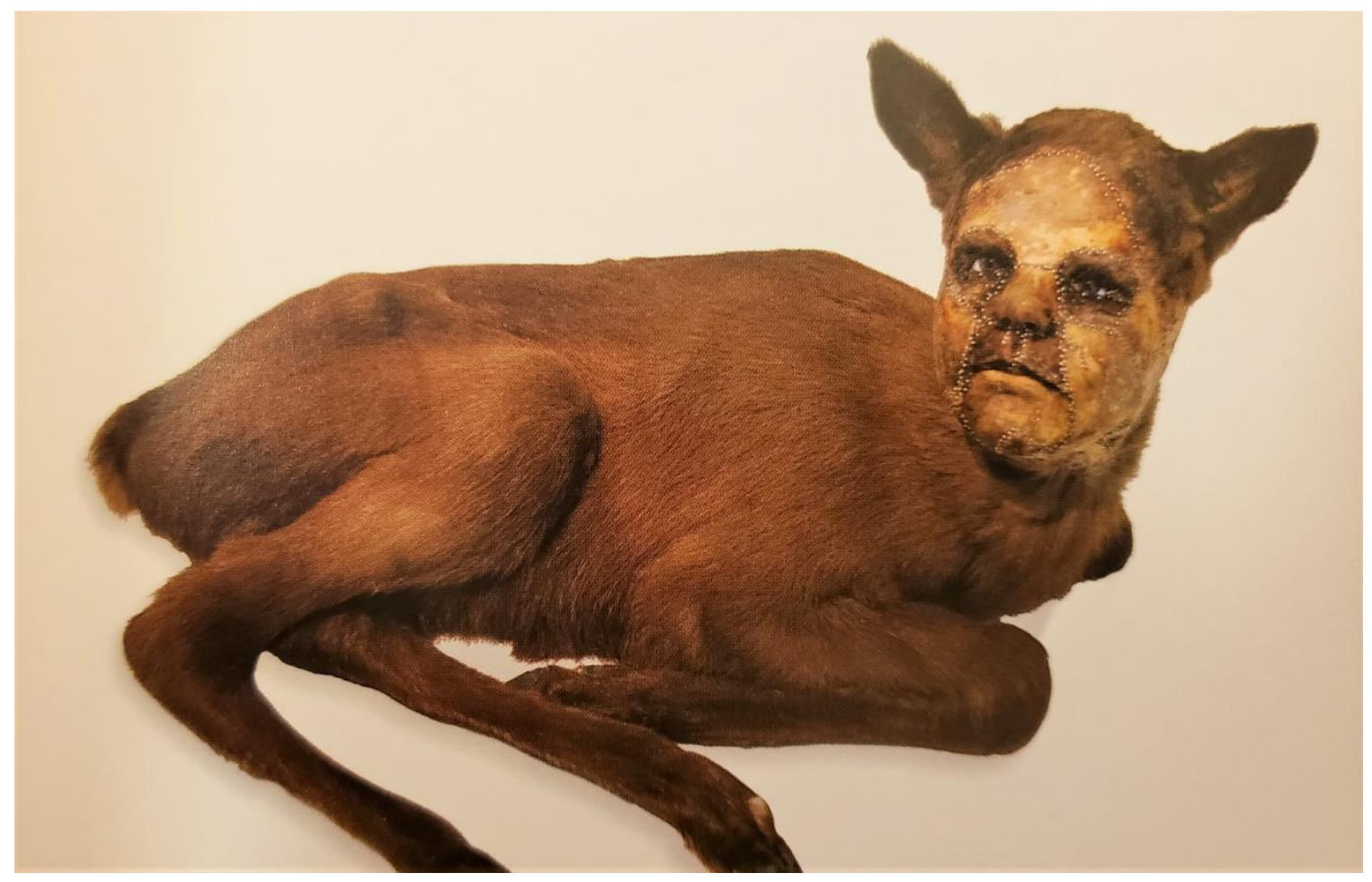

Clark, Kate. Little Girl, from Citizen: An American Lyric, page 19. 
Appendix E: "Match" from Deaf Republic

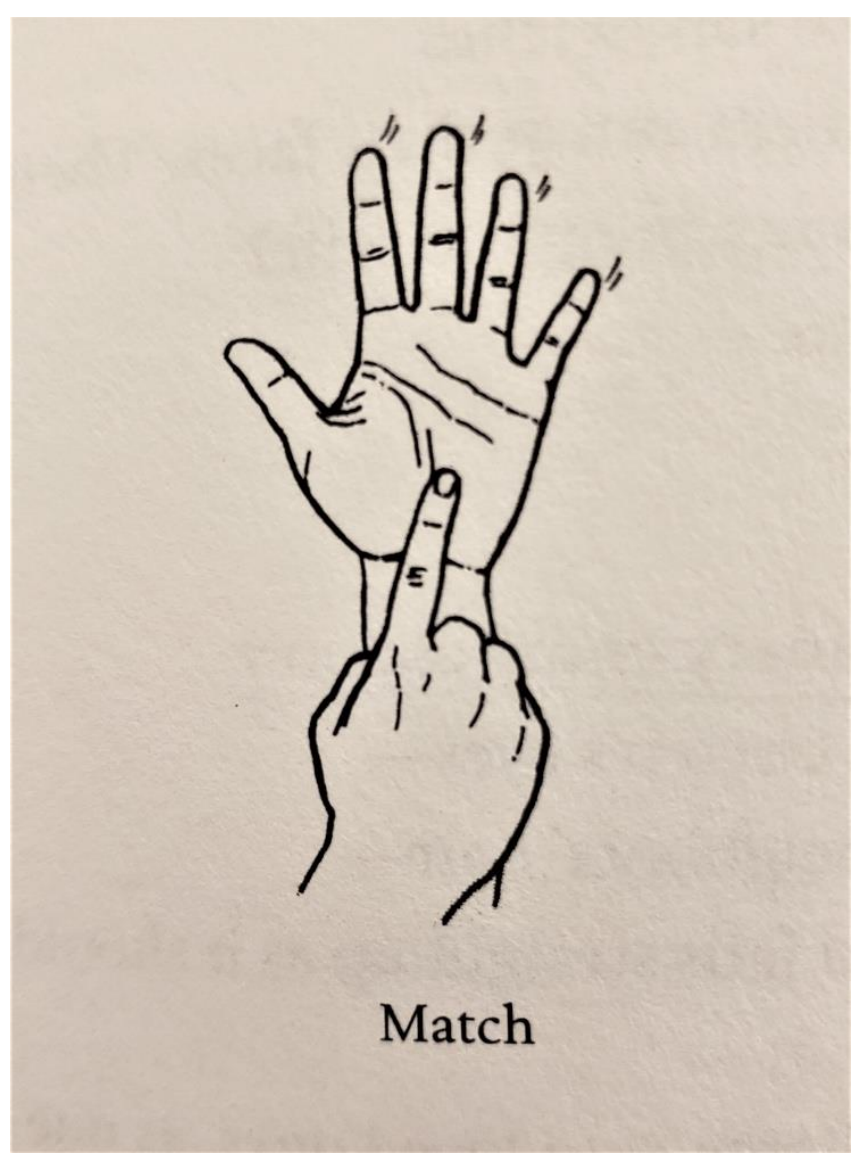

Photo of "Match" by Jennifer Whitten from Deaf Republic, Graywolf Press, page 26. 


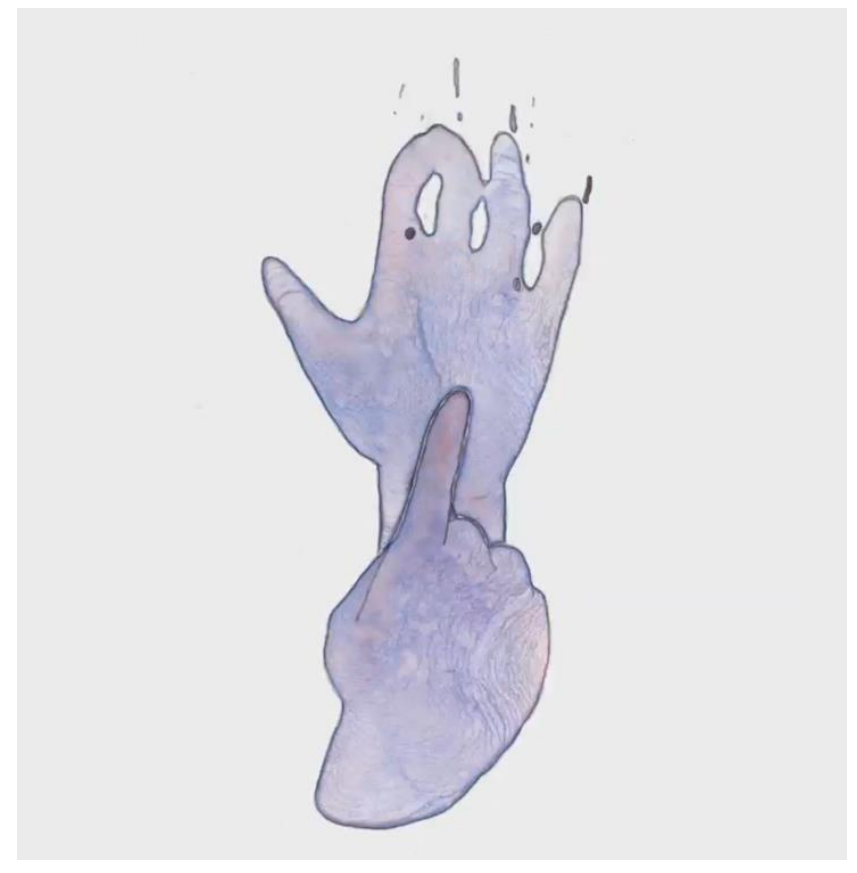

Screenshot 1 of "Match" by Miwon Yoon in mid-loop. The New Yorker.

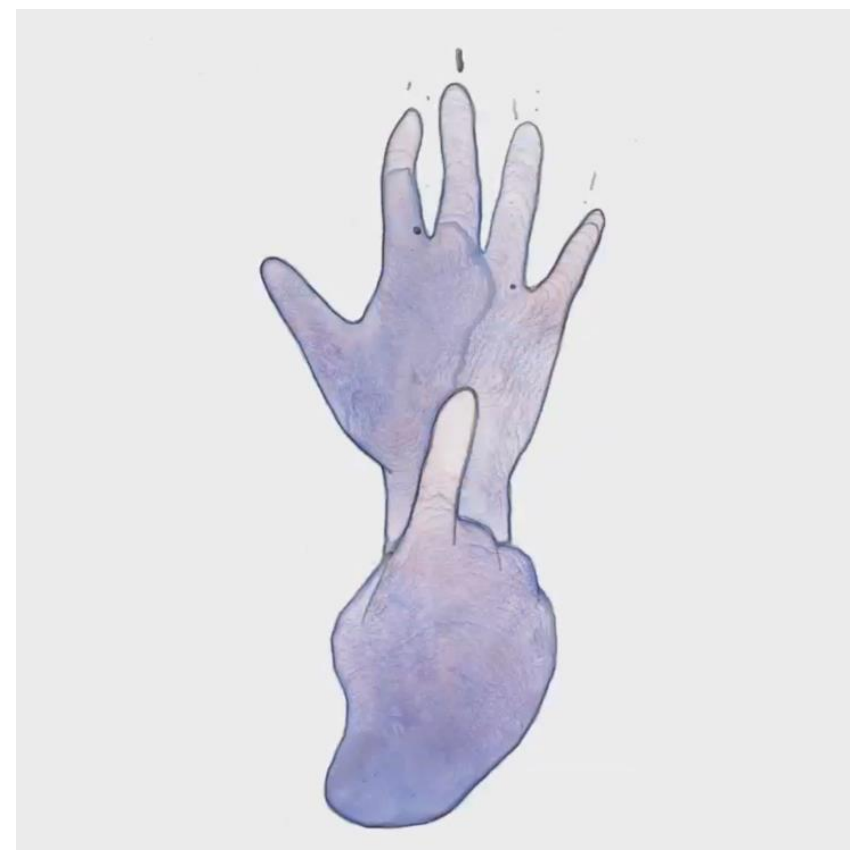

Screenshot 2 of "Match" by Miwon Yoon in mid-loop. The New Yorker. 
Appendix F: Solely Illustrations Page from Deaf Republic
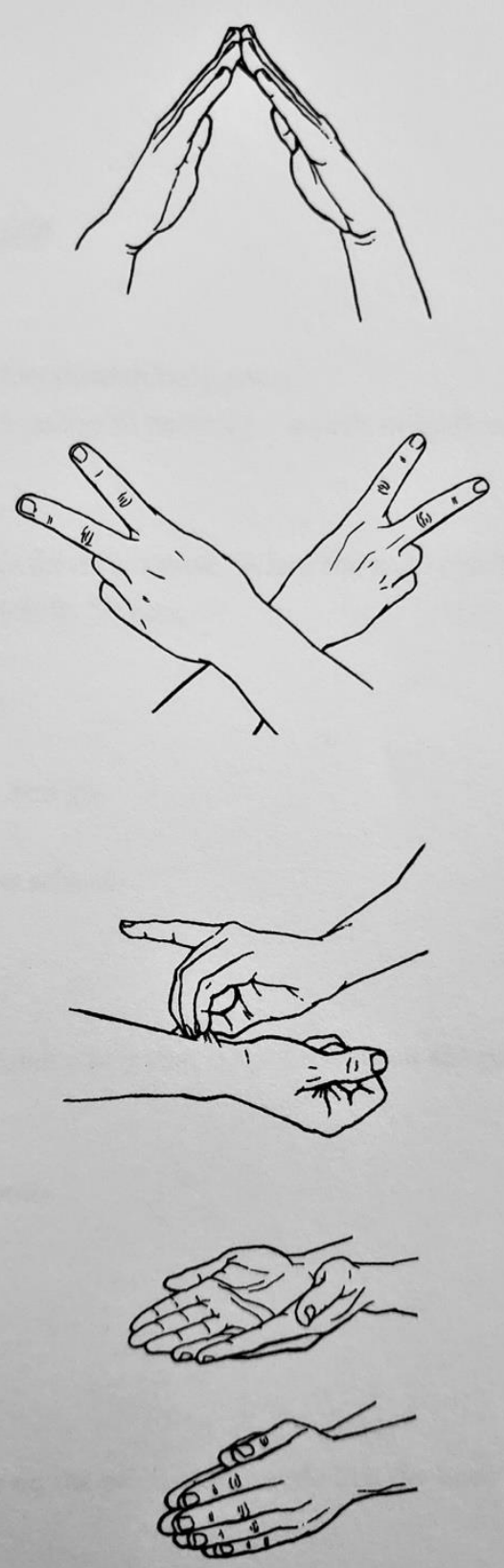

Photo of Deaf Republic, page 73. Note "story" displayed by the last two sets of hands. 
Appendix G: "Story" from Deaf Republic

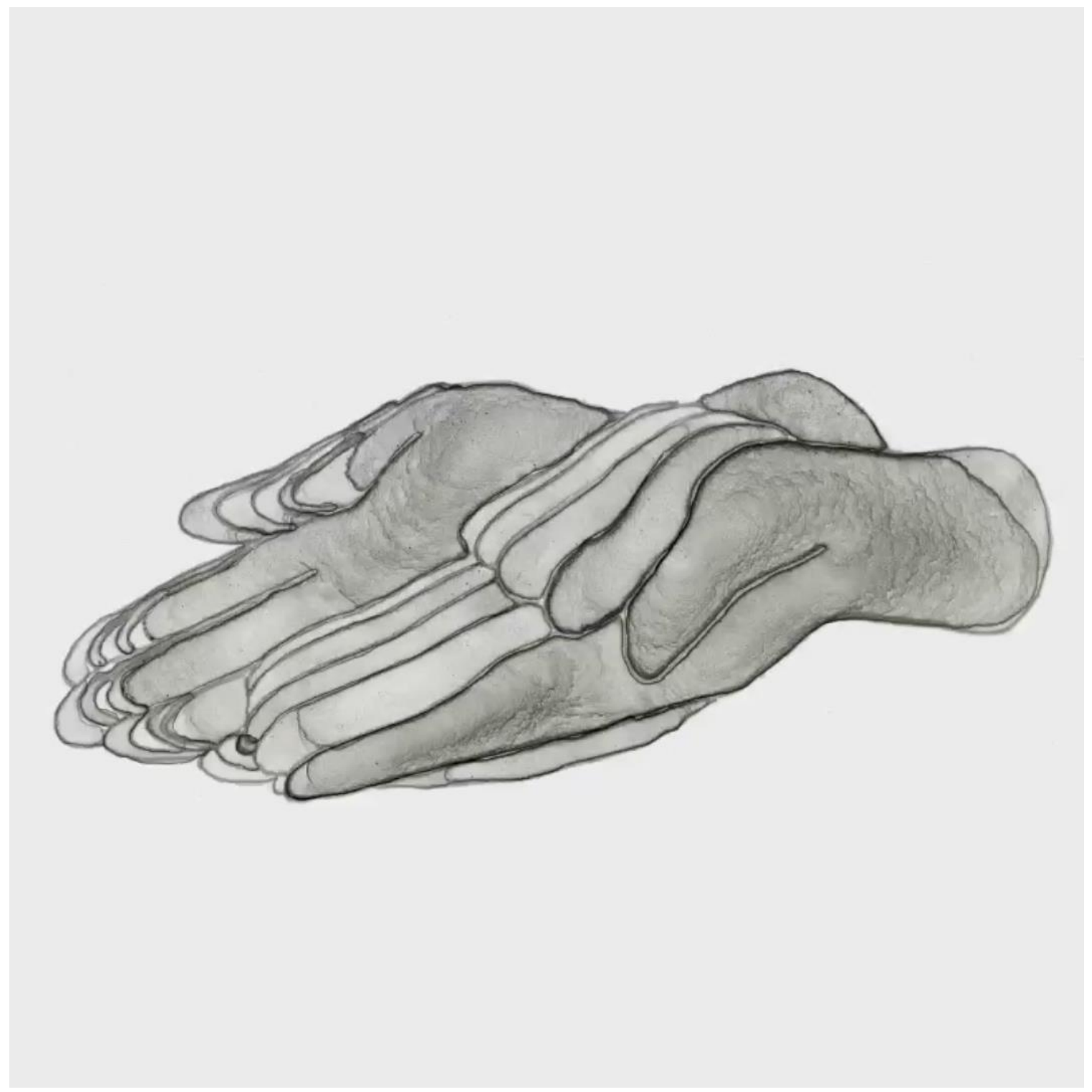

Screenshot of "Story" by Miwon Yoon mid-loop. The New Yorker. Note the darker shade on the outside, showing that the hands are moving outward. 


\section{References}

Adams, Bella. 'Black Lives/White Backgrounds: Claudia Rankine's Citizen: An American Lyric and Critical Race Theory." Comparative American Studies An International Journal, December 2017, pp 54-71.

Armitstead, Claire. “'I will never hear my father’s voice’: Ilya Kaminsky on deafness and escaping the Soviet Union.” The Guardian. 2019. Web. https://www.theguardian.com/books/2019/jul/19/ilya-kaminsky-interview

Burt, Stephen. the poem is you: 60 Contemporary American Poems and How to Read Them. Cambridge: The Belknap Press, 2016. Print.

Cixous, Hélène, et al. “The Laugh of the Medusa.” Signs, vol. 1, no. 4, 1976, pp. 875-893. JSTOR, www.jstor.org/stable/3173239. Accessed 2 July 2020.

Day, Ikyo. "Unnatural Landscapes: Romantic Anticapitalism and Alien Degeneracy," Alien Capital: Asian Racialization and the Logic of Settler Colonial Capitalism. Duke University Press, March 2016, pp 73-114.

Evanston Review Newspaper, “"Lease to Jap Americans Ended: Dr. McKibben Makes Statement" Newspaper Article," Yamashita Family Archives. https://yamashitaarchives.ucsc.edu/items/show/3328. Accessed 4 July 2020. Web. Foote, Caleb. “Outcasts! Publication.” Yamashita Family Archives. https://yamashitaarchives.ucsc.edu/items/show/3330. Accessed 4 July 2020. Web. Kaminsky, Ilya. Deaf Republic: Poems. Minneapolis: Graywolf Press, 2019. Print.

Kaminsky, Ilya and Miwon Yoon. "From 'Deaf Republic."” The New Yorker. 2019. Web. https://www.newyorker.com/magazine/2019/02/18/deaf-republic 
Kress, Gunther R., Theo van Leeuwen. Reading Images: The Grammar of Visual Design. London: Routledge, 2010. Print.

Lerner, Ben. The Hatred of Poetry. New York: Ferrar, Straus and Giroux, 2016. Print.

Lowe, Lisa. "Heterogeneity, Hybridity, Multiplicity: Marking Asian American Differences." Diaspora: A Journal of Transnational Studies, vol. 1 no. 1, 1991, p. 24-44. Project MUSE, doi:10.1353/dsp.1991.0014.

Mitchell, W.J.T. "Ekphrasis and the Other." Picture Theory. Chicago: University of Chicago Press, 1994. Web. https://complit.utoronto.ca/wp-content/uploads/COL1000-Week11Nov25_WJT_Mitchell.pdf. Accessed 11 December 2019.

Postman, Neil, and Andrew Postman. Amusing Ourselves to Death: Public Discourse in the Age of Show Business. New York, N.Y., U.S.A: Penguin Books, 2006. Print.

Rankine, Claudia. Citizen: An American Lyric. Minneapolis: Graywolf Press, 2014. Print. Rankine, Claudia. "In 'Citizen,' Poet Strips Bare the Realities of Everyday Racism.” NPR, 3 January 2015. https://www.npr.org/2015/01/03/374574142/in-citizen-poet-strips-barethe-realities-of-everyday-racism. Accessed 7 June 2020.

Rankine, Claudia. Interview by Lauren Berlant. BOMB Magazine. 1 October 2014. https://bombmagazine.org/articles/claudia-rankine/. Accessed 9 June 2020.

Rankine, Claudia, Beth Loffreda, and Max K. Cap. The Racial Imaginary: Writers on Race in the Life of the Mind. New York: Fence Books. 2015. Print.

Saussure, Ferdinand de. "Course in General Linguistics.” Leitch, Vincent B, William E. Cain, Laurie Finke, John McGowan, T D. Sharpley-Whiting, and Jeffrey Williams. The Norton Anthology of Theory and Criticism, 2018. 824-840. Print.

Shakespeare, William, et al. The Norton Shakespeare. New York: W.W. Norton, 2008. Print. 
Sontag, Susan. "Looking at War: Photography's view of devastation and death." The New Yorker. 2002. Web. https://www.newyorker.com/magazine/2002/12/09/looking-at-war Sontag, Susan. On Photography. New York, NY: Picador, 1977. Print.

Ulin, David L. "Poet Claudia Rankine ruminates on the body politic in 'Citizen.'” Los Angeles Times. 9 October 2014. Web. https://www.latimes.com/books/jacketcopy/la-ca-jcclaudia-rankine-20141012-story.html. Accessed 21 July 2020.

Yamashita, Karen Tei. Letters to Memory. Coffee House Press, 2017. Print. 


\section{Works Consulted}

Althusser, Louis, Etienne Balibar, Jacques Bidet, and G M. Goshgarian. On the Reproduction of Capitalism: Ideology and Ideological State Apparatuses. London: Verso, 2014. Print.

Barthes, Roland. "The Death of the Author." Leitch, Vincent B, William E. Cain, Laurie Finke, John McGowan, T D. Sharpley-Whiting, and Jeffrey Williams. The Norton Anthology of Theory and Criticism, 2018. 1268-1272. Print.

Bhabha, Homi K. The Location of Culture. Abingdon: Routledge, 1994. Print.

Foucault, Michel. "What is an Author?" Leitch, Vincent B, William E. Cain, Laurie Finke, John McGowan, T D. Sharpley-Whiting, and Jeffrey Williams. The Norton Anthology of Theory and Criticism, 2018. 1394-1409. Print.

Hoagland, Tony. "Dear Claudia: A Letter in Response." 2011. Poets.org. https://www.poets.org/poetsorg/text/dear-claudia-letter-response. Accessed 7 September 2017. Web.

Hoagland, Tony. “The Change.” What Narcissism Means to Me. Graywolf Press, 2003.

Mitchell, W. J. T. Iconology: Image, Text, Ideology. Chicago: University of Chicago Press, 1987. Print.

Morrison, Toni. Playing in the Dark: Whiteness and the Literary Imagination. New York: Vintage Books, Random House, Inc., 1993. Print.

Rankine, Claudia. "Open Letter: A Dialogue on Race and Poetry.” 4 February 2011. Poets.org. https://www.poets.org/poetsorg/text/open-letter-dialogue-race-and-poetry. Accessed 7 September 2017. Web. 
Sender, Katherine, and Peter Decherney. "Stuart Hall lives: cultural studies in the age of digital media." Critical Studies in Media Communication. Volume 33. Taylor \& Francis, 2016. Web. Accessed 09 December 2019.

Sontag, Susan. “Against Interpretation.” Against Interpretation. Farrar, Straus and Giroux, 1966. Print.

Zerubavel, Eviatar. Social Mindscapes: An Invitation to Cognitive Sociology. Harvard University Press, 2011. Print. 